\title{
Article
}

\section{Evidence of substrate roughness surface induced magnetic anisotropy in Ni80Fe20 flexible thin films}

Beluskya, M, Lepadatu, Serban, Naylorc, J and Vopsona, MM Available at http://clok.uclan.ac.uk/26046/

Beluskya, M, Lepadatu, Serban ORCID: 0000-0001-6221-9727, Naylorc, J and Vopsona, MM (2019) Evidence of substrate roughness surface induced magnetic anisotropy in Ni80Fe20 flexible thin films. Journal of Magnetism and Magnetic Materials, 478 . pp. 77-83. ISSN 0304-8853

It is advisable to refer to the publisher's version if you intend to cite from the work. http://dx.doi.org/10.1016/j.jmmm.2019.01.097

For more information about UCLan's research in this area go to http://www.uclan.ac.uk/researchgroups/ and search for <name of research Group>.

For information about Research generally at UCLan please go to http://www.uclan.ac.uk/research/

All outputs in CLoK are protected by Intellectual Property Rights law, including Copyright law. Copyright, IPR and Moral Rights for the works on this site are retained by the individual authors and/or other copyright owners. Terms and conditions for use of this material are defined in the policies page. 


\title{
Evidence of substrate roughness surface induced magnetic anisotropy in $\mathrm{Ni}_{80} \mathrm{Fe}_{20}$ flexible thin films
}

\author{
$\underline{\text { M. Belusky }}^{1}$, S. Lepadatu ${ }^{2}$, J. Naylor ${ }^{3}$, M.M. Vopson ${ }^{1}$ \\ ${ }^{1}$ University of Portsmouth, SEES, Faculty of Science, Portsmouth PO1 3QL, UK \\ ${ }^{2}$ University of Central Lancashire, Jeremiah Horrocks Institute for Mathematics, Physics and Astronomy, \\ Preston PR1 2HE, UK \\ ${ }^{3}$ Kurt J Lesker Ltd, 15/16 Burgess Road, Hastings, East Sussex, TN35 4NR, UK
}

\begin{abstract}
Experimental and computational evidence of a surface roughness induced magnetic anisotropy in NiFe thin films coated onto substrates of various surface roughnesses is reported. Magnetic coercive fields of $15 \mathrm{~nm} \mathrm{NiFe}$ thin films coated on substrates with approximately $7 \mathrm{~nm}$ average roughness were remarkably 233\% larger than identical thin films coated onto smooth substrates with $<1 \mathrm{~nm}$ average roughness. The NiFe films coated onto rough substrates developed hard and easy axes, normally non-existent in $\mathrm{NiFe}$ Permalloy. A linear correlation of the incline angles of the hard axis hysteresis loops to the average roughness values of the individual substrates was observed, with $99 \%$ correlation level. Using a modified micromagnetics theory that incorporates the effects of surface roughness, it is shown the observed magnetic anisotropy arises due to the spatial anisotropy of the surface roughness, resulting in an effective in-plane uniaxial magnetic anisotropy with energy density up to $15 \mathrm{~kJ} / \mathrm{m}^{3}$.
\end{abstract}

Keywords: Surface roughness, Flexible magnetic film, Magnetic anisotropy, NiFe, Plasma sputtering, Micromagnetics of surface roughness 


\section{Introduction}

Thin films have been influential to human culture since the ancient past, when Egyptians used gold beating techniques to cover decorative items such as royal crowns [1]. Owing to scientific developments and discoveries of new materials, the significance of films has shifted from art to technology. In present times, most of engineering disciplines incorporate the use of thin films in various applications including thin film photovoltaics for efficient solar power conversion [2-7], thin film lithium batteries for consumer portable electronics [8,9], semiconductor thin films for micro- and nano-electronics [10], thin film optical coatings [11], thin films for high resolution displays [12] and thin films for tribological and protective coatings applications [13], to name a few.

However, one of the most successful application of thin film technologies is in digital data storage, where thin films are utilized for magnetic data storage in hard disc drive devices [14], or in solid-state data storage as memory cells made up of thin film transistors and capacitors [15]. In fact, magnetic thin films are essential not only for magnetic data storage but also for other technologies involving magnetic actuation [16], thin film inductors [17], magnetic sensing and security devices [18-20].

To achieve desired functionalities, magnetic thin films must be fabricated with precise and controllable properties such as coercive field $\left(\mathrm{H}_{\mathrm{c}}\right)$, saturation magnetisation $\left(\mathrm{M}_{\mathrm{s}}\right)$ and the magnetization reversal profile of the hysteresis loop. Various commonly used control methods of these parameters are doping [21], the use of suitable substrates [22] and seed layers [23] and thermal annealing [24] during and post deposition. A highly influential control mechanism of magnetism in thin films is also the actual process of thin film coating, together with the choice of deposition parameters. In the case of magnetic thin films fabricated via plasma sputtering, it has been shown that the deposition rates $[25,26]$, substrate 
temperature, bias voltage, plasma power, base pressure and process gas pressure have a significant effect on the final magnetic thin film's properties. The list of controllable parameters of magnetic thin films is further complicated when one attempts to deposit flexible magnetic thin films. Mechanical flexibility of a material is a key property that opens up new possibilities for existing and new inventions alike. Flexible thin films are already firmly established in the form of flexible solar cells [27], flexible displays [28] and flexible medical or gas monitoring sensors [29-31]. Recently there have been a number of studies of magnetic flexible thin films and their properties [32,33], in which the flexibility was achieved by depositing magnetic thin films onto flexible substrates. Magnetic properties, such as anisotropy or coercive field, often exhibit unusual characteristics in thin films compared to that of a bulk material [34]. These can arise, besides other means, from shape effects, residual stress created during the film growth or interactions of atoms at the surface. The use of flexible substrates further enhances these interfacial effects. A dependence of coercive field value on film thickness, for various ferromagnetic materials grown on a solid substrate, has been extensively described in many studies [35-37]. A low surface roughness has been linked to a small coercive field [38]. Similar to this, recent research involving magnetic thin films coated onto flexible substrates has found that both film thickness and substrate roughness play a significant role in their properties [39]. NiFe films grown on flexible substrates of different roughness values implied that rougher surfaces promote higher coercive fields of the thin film [40]. The proposed mechanism driving this effect was explained theoretically by Lepadatu using a modified Landau-Lifshitz-Gilbert (LLG) micromagnetics approach [41] and involves a surface induced magnetic anisotropy in magnetic thin films by the surface roughness of the substrate. In this paper we report additional studies of flexible NiFe thin films and we offer experimental and theoretical proof that a surface induced anisotropy is indeed responsible for the observed results. 


\section{Experiment}

LabLine SPUTTER 5 magnetron plasma sputtering from K.J.Lesker [42] has been used to coat the $\mathrm{Ni}_{80} \mathrm{Fe}_{20}$ thin films onto Silicon (Si) wafer (100) solid substrate chosen as reference, and two flexible substrates: a Kapton $(50 \mu \mathrm{m})$ and Polyvinylidene fluoride (PVDF) $(110 \mu \mathrm{m})$, respectively. Kapton is a Silicon based polyimide with good temperature resistance up to $400^{\circ} \mathrm{C}$ and popular in many applications requiring flexibility and high temperature resistance. PVDF is a flexible piezoelectric material very useful for development of functional composites including multiferroic composites. The vacuum chamber base pressure for each sample was $1.7 \times 10^{-7}$ Torr and the temperature of the substrate was monitored and kept constant at $27{ }^{\circ} \mathrm{C}$ during the deposition processes. An RF plasma cleaning procedure was applied to all substrates using 50W RF power, argon gas process pressure of $10 \times 10^{-3}$ Torr and 2 minutes plasma cleaning duration per substrate. All substrates were then coated with 5 nm seed layer of Chromium (Cr) for improved adhesion. The $\mathrm{Cr}$ seed layers were all coated using the following conditions: Argon gas process pressure set to $3 \times 10^{-3}$ Torr, DC power $50 \mathrm{~W}$ and the growth rate was measured by quartz crystal to be around $2 \AA / \mathrm{sec}$. Our Kurt J. Lesker plasma sputtering tool is designed to accommodate in its vacuum chamber up to four substrates that can be coated individually without venting the chamber. A carousel holding the substrates automatically rotates each substrate to the appropriate position above the magnetron target. The system can accommodate five magnetron targets (four DC including a high magnetic field magnetron and one RF), which are located at around $10 \mathrm{~cm}$ distance below the substrates carousel. 
In our initial studies reported in [40], we coated NiFe films having the following structure: Substrate / Cr (5 nm) / NiFe (t nm) where Substrate is Si, Kapton and PVDF, respectively and the thickness variable was $\mathrm{t}=$ $100 \mathrm{~nm}, 60 \mathrm{~nm}$ and $15 \mathrm{~nm}$, respectively. Room temperature Magneto-Optic Kerr Effect (MOKE) was used to measure magnetic hysteresis loops of all samples. Maximum field of 650 Oe was applied to drive the samples to saturation. MOKE signal fluctuation in our particular setup is under

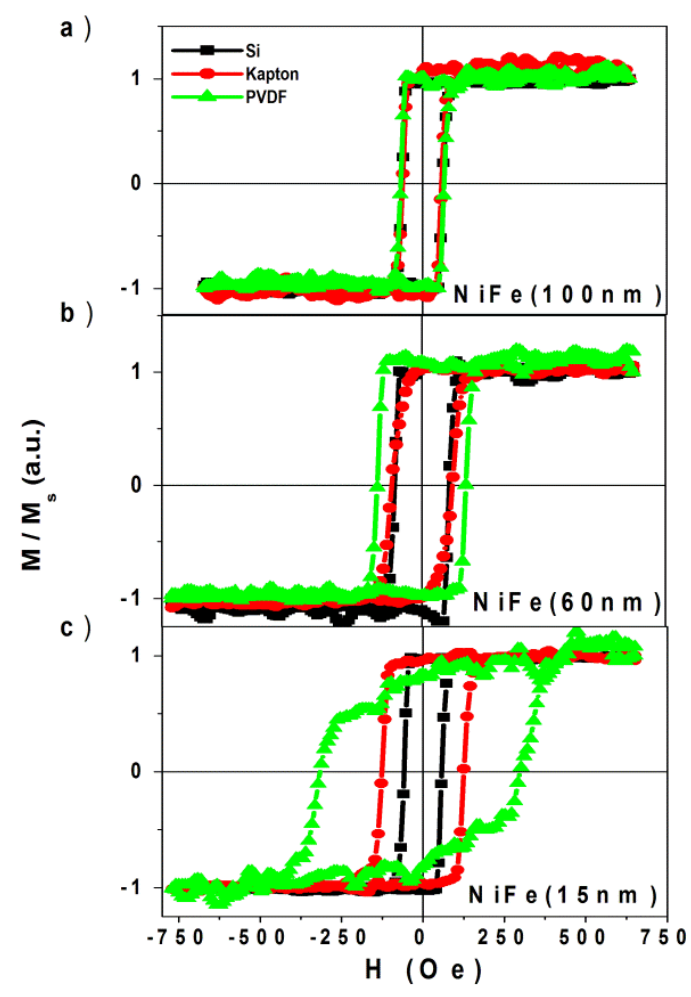

Figure 1. Comparison of magnetic hysteresis loops for NiFe a) $\mathrm{t}=100 \mathrm{~nm}$; b) $\mathrm{t}=60 \mathrm{~nm}$; c) $\mathrm{t}=15 \mathrm{~nm}$; for Si, Kapton and PVDF substrates.

\section{$0.1 \%$, achieved by deploying an electro-optic}

noise reduction modulator known as "noise eater", which allowed us to obtain hysteresis loops in a single measurement, without averaging, in less than a minute per hysteresis loop.

Figures 1.a) to 1.c) show a comparison study of magnetic hysteresis loops for 100, 60 and 15 $\mathrm{nm} \mathrm{NiFe}$ films, deposited on the three aforementioned substrates. Figure 1.a) shows that 100 $\mathrm{nm} \mathrm{NiFe}$ thin films display identical magnetization reversal profile and coercive fields of around $67 \mathrm{Oe}$, regardless of the type of substrate used. As the thickness of the NiFe films is reduced to $60 \mathrm{~nm}$, the films coated onto Kapton and Si substrates appear to display identical behaviour, while the film coated onto PVDF substrate shows a clear increase in the coercive field to 135 Oe (see figure 1.b). Upon further decreasing the thickness of $\mathrm{NiFe}$ down to 15 $\mathrm{nm}$, a clear trend is observed in which both NiFe films coated onto Kapton and PVDF show a significant increase in their coercive fields to 126 Oe and 306 Oe, respectively, while the coercive field of $\mathrm{NiFe}$ on $\mathrm{Si}$ remains broadly unchanged. This corresponds to $88 \%$ and 356 $\%$, respectively enhancement of the coercive field of $\mathrm{NiFe}$ thin films when compared to those 
deposited onto Si substrates. These initial results were connected to the substrate roughness values [40], in which it was suggested that surface roughness may be responsible for the coercive field enhancement due to a surface induced magnetic anisotropy, as shown theoretically by Lepadatu [41]. This is further supported by the thickness data that shows a total cancelation of the effect for thicker $(100 \mathrm{~nm})$ films in which the nano-scale substrate roughness effects are negligible, and a gradual emergence when the thickness is reduced and the surface roughness begins to dominate. A maximum effect appears to be achieved when the film thickness is of the order of magnitude of the surface roughness.

Hence, to clarify this aspect, we focus our studies on the thinner NiFe films where the surface roughness effect appears to dominate. If a surface roughness induced magnetic anisotropy is indeed responsible for the observed results, this should be identifiable in the magnetic hysteresis data via the emergence of hard axis (HA) and easy axis (EA) magnetization reversal profiles. To prove this experimentally we fabricated a new set of NiFe $15 \mathrm{~nm}$ thin films using the same deposition conditions as described above. However, in order to optimize the deposition process, we have varied the DC sputtering power, which resulted in a variation of the thin film growth rate from $1 \AA / \mathrm{s}$ at $25 \mathrm{~W}$ power to $3.8 \AA / \mathrm{s}$ at $100 \mathrm{~W}$, as shown in Table 1 .

Table 1. Deposition conditions and code names for the $15 \mathrm{~nm} \mathrm{Ni}{ }_{80} \mathrm{Fe}_{20}$ thin films.

\begin{tabular}{|c|c|c|}
\hline $\begin{array}{c}\text { DC sputtering Power } \\
(\mathbf{W})\end{array}$ & $\begin{array}{c}\text { Sample code names } \\
\text { (Substrate }=\text { Silicon, Kapton, PVDF) }\end{array}$ & $\begin{array}{c}\text { Grow rate } \\
(\mathbf{\AA} / \mathbf{s})\end{array}$ \\
\hline 100 & Substrate_100 & 3.8 \\
\hline 75 & Substrate_75 & 2.9 \\
\hline 50 & Substrate_50 & 1.9 \\
\hline 25 & Substrate_25 & 1.0 \\
\hline
\end{tabular}

The samples structure is: Substrate / Cr $(5 \mathrm{~nm})$ / NiFe $(15 \mathrm{~nm})$, where Substrate is Si, Kapton and PVDF, respectively. Table 1 shows the samples code names and their deposition conditions used as variables. Surface morphology and substrates roughness were evaluated using a Park NX10 Atomic Force Microscope (AFM). Each measured area was 5 x $5 \mu \mathrm{m}$ using a non-contact scanning mode and XEI software was used to process the data and to extract the average roughness values. 


\section{Results and discussions}

All three substrates used in these studies have a very different surface roughness with average roughness values, $\mathrm{Ra}$, for $\mathrm{Si}$ of around $2 \mathrm{~nm}$, Kapton around $5 \mathrm{~nm}$, and PVDF of around $8 \mathrm{~nm}$, as also previously reported [40]. However, these are the values before substrate plasma cleaning procedure is deployed and we observed a surface roughness modification of the substrates after this process. Hence, we retested our substrates immediately after the plasma cleaning procedure in order to get a more accurate value of their surface roughness in the final samples. Figure 2 shows the 3D topography of our substrates after the plasma cleaning procedure, measured with an AFM in non-contact scanning mode. After plasma treatment, average roughness of silicon substrate decreased to $\mathrm{R}_{\mathrm{a}}=0.6 \mathrm{~nm}$,

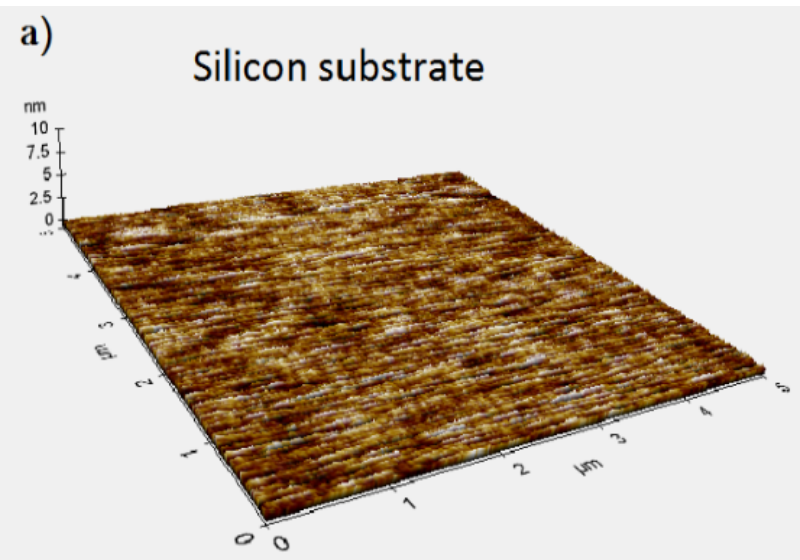

b) Kapton substrate

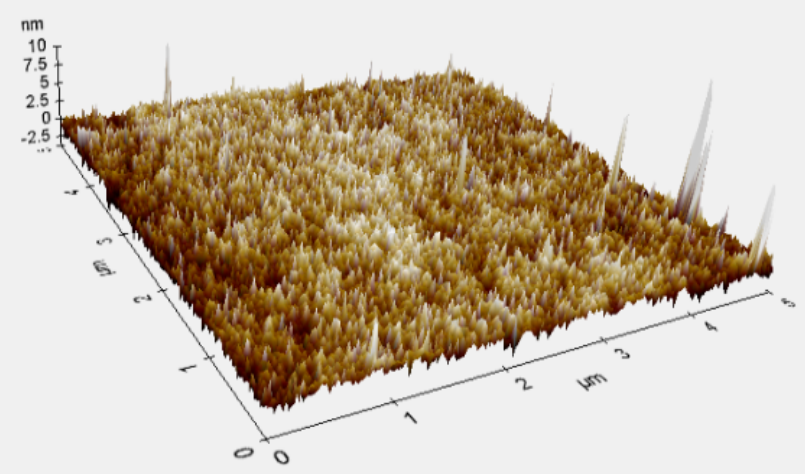

c) PVDF substrate

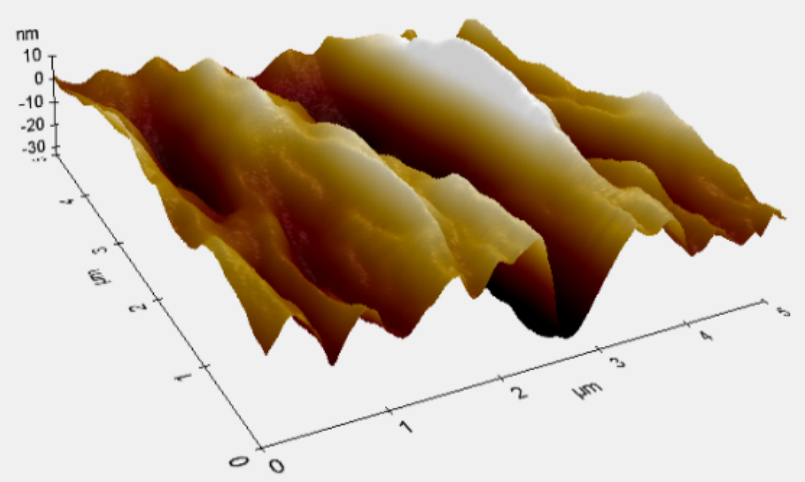

Figure 2. AFM images for all three substrates after plasma cleaning. a) Silicon; b) Kapton; c) PVDF.

flexible Kapton reduced to $R_{a}=2.2 \mathrm{~nm}$

and PVDF roughness became $6.8 \mathrm{~nm}$ (see figure 2). A closer examination of figure 2 clearly indicates a distinct 'wave-like' character of PVDF substrate roughness, where the material 
surface shows a number of deep ridges not uniformly levelled and not seen in the other Kapton and Si substrates.

It is important to mention that these values are very much susceptible to the plasma cleaning process in terms of plasma power and most importantly the duration of the Ar plasma exposure. This process also affects materials in different ways depending on their structure. Solid substrates such as silicon wafer tolerate ion bombardment to a greater degree and the result is surface cleaning rather than etching. In the case of polymers, shorter cleaning times may enhance the surface properties whilst longer exposures promote damage by high-energy ions. This is not surprising as plasma cleaning of polymer type materials result in etching process, polymer chains breaking [43] significantly increasing their surface free energy [44]. Longer exposure times often lead to drastic modification of the samples and increase in surface roughness, especially in PVDF, which has a low melting temperature of around 120 ${ }^{0} \mathrm{C}$. After the plasma treatment of the substrates, $5 \mathrm{~nm}$ seed layer of $\mathrm{Cr}$ was coated onto each substrate, followed by deposition of $15 \mathrm{~nm}$ of NiFe thin films at four different dc sputtering powers, as described in the previous section (see table 1), giving a total of 12 samples. Figure 3 shows the magnetic hysteresis loops obtained via MOKE measurements for all samples. Individual graphs consist of 4 loops, each relating to the sputtering power used during deposition. By rotating the sample axis 90 degrees relative to the applied magnetic field vector (see fig. 4), we were able to identify and test magnetic hysteresis response for easy axis (EA) and hard axis (HA), respectively. Interestingly, the samples sputtered onto $\mathrm{Si}$ substrates show no magnetic anisotropy and identical HA/EA magnetic coercive field values regardless on the sputtering power (see figures 3.a) and d)). 
$\underline{H}$ ard a $x$ is
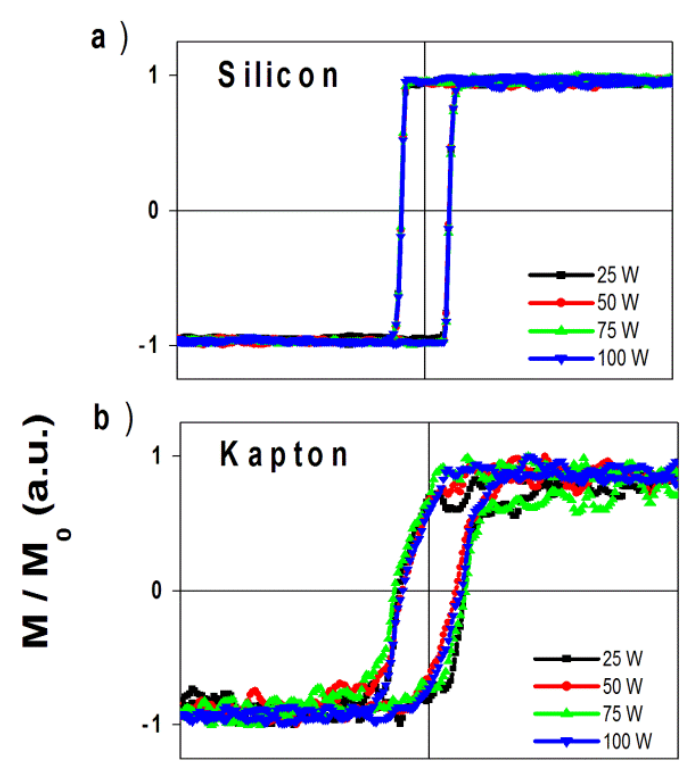

c)

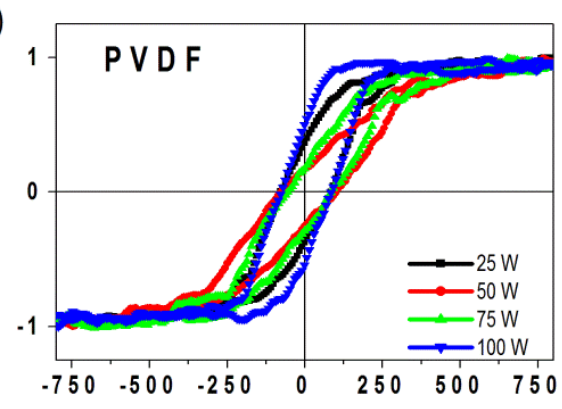

E asy axis

d)

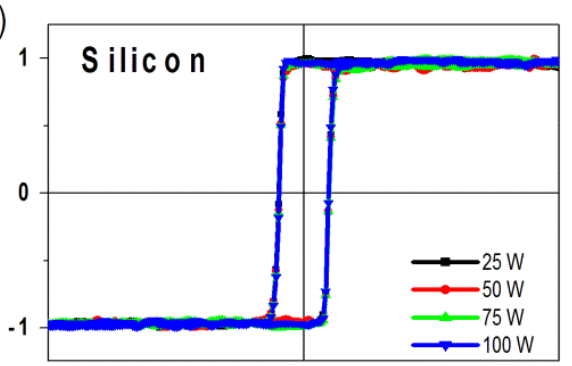

e )

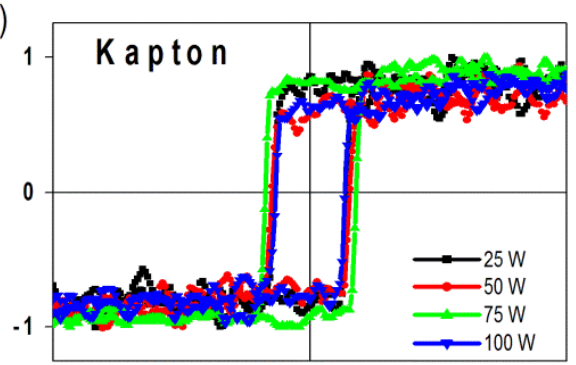

f)

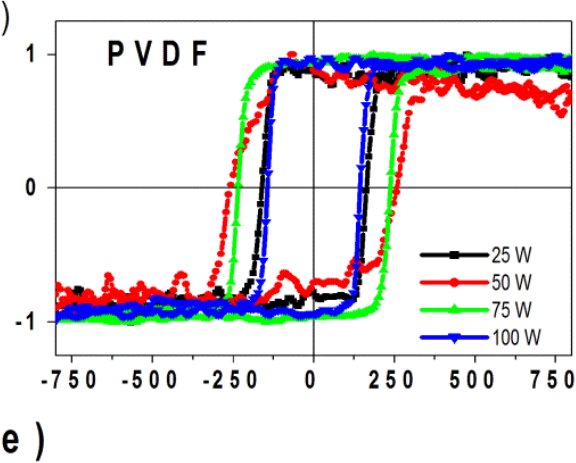

Figure 3. Hysteresis loops for $15 \mathrm{~nm} \mathrm{NiFe}$ on $\mathrm{Si}$, Kapton and PVDF, coated at 25W, 50W, 75W and $100 \mathrm{~W}$ dc sputtering power. Figures a) $-\mathrm{c}$ ) represent the HA response and figures $\mathrm{d})-\mathrm{f}$ ) represent the EA hysteresis loops.

The magnetic reversal profile of $\mathrm{NiFe}(15 \mathrm{~nm})$ coated onto Kapton and PVDF, clearly shows a distinctive response with square hysteresis loops measured in the EA orientation and tilted loops in the HA direction. In the case of Kapton, while the magnetic coercive field increases relative to that on Si substrates, it appears that the HA loops inclinations, as well as the magnetic coercive fields are not influenced by the sputtering power (see figures 3.b) and e)).

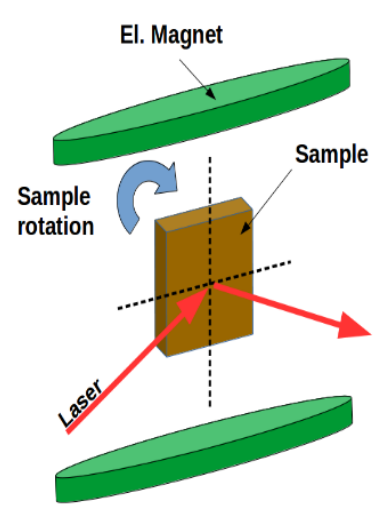

Figure 4. Sample measurement geometry for MOKE testing 
The emergence of magnetic anisotropy is even more obvious for NiFe on PVDF substrates where the inclinations of the HA hysteresis loops are more pronounced and the largest coercive field values of EA hysteresis loops are $233 \%$ larger than those of identical samples coated onto $\mathrm{Si}$ substrates. This is exactly the expected behaviour if the substrate roughness is indeed the driving mechanism for the remarkable magnetic coercive field

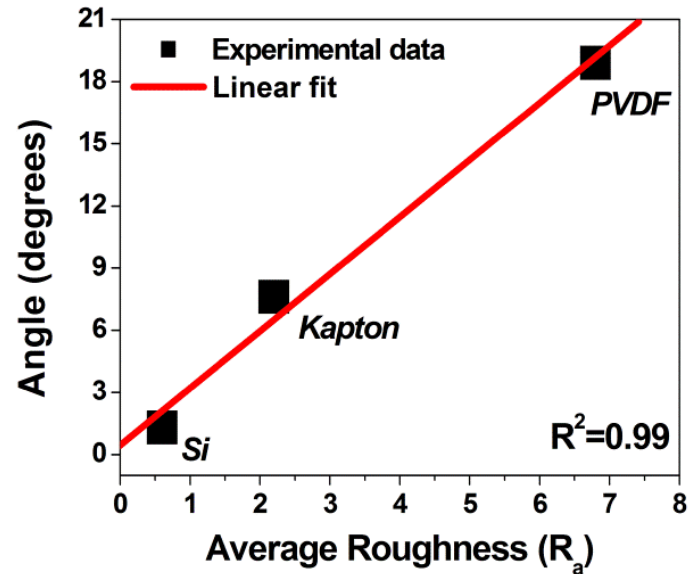

Figure 5. Roughness values of individual substrates related to the average incline angle of their corresponding HA hysteresis loops.

enhancement, due to an induced surface magnetic anisotropy. NiFe permalloy is well known soft magnetic material with very small / negligible magnetocrystalline anisotropy [45], and the underlying mechanisms are still a matter of research today $[45,46]$. In our case, however, the distinct anisotropy appears only in flexible substrates with large surface roughness, even though all samples underwent identical sputtering conditions. The higher the substrate roughness, the larger the induced surface anisotropy appears to be, while for smooth Si substrates the effect vanishes completely. It is therefore a powerful argument to assume that the type of substrate, or rather its roughness, is responsible for the observed magnetic

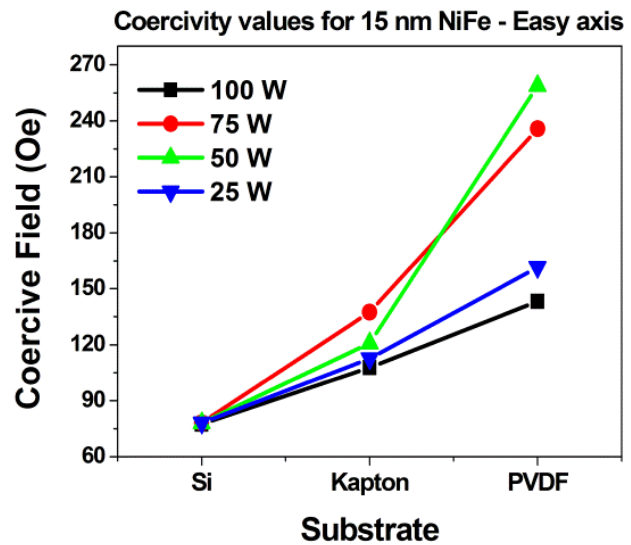

Figure 6. EA coercivity values measured for $\mathrm{NiFe}$ coated on Si, Kapton and PVDF substrates at different dc sputtering power. Each sputtering power produces a different $\mathrm{H}_{\mathrm{c}}$ value, but clearly the larger the roughness, the larger the $\mathrm{H}_{\mathrm{c}}$.

changes and surface induced anisotropy. To further enforce this assumption, the incline angles of the HA hysteresis loops were determined and correlated to the roughness values of the individual substrates. The incline angle of a given HA hysteresis loop was taken as the 
angle deviation from the vertical magnetization axis to the tangential line linking positive and negative magnetization saturation points on the HA hysteresis loops. For each substrate, we determined the inclination angle corresponding to each sputtering power and we calculated its average value. By plotting the average incline angle of the HA versus the substrate roughness we obtained a strong linear correlation, with a correlation factor of $99 \%$ (see figure 5 and figures 3.a) to c)), which is a significant indication that the surface induced magnetic anisotropy is indeed correlated to the surface roughness.

While the HA hysteresis curves display a clear correlation to the substrate roughness, their coercive fields are mostly unchanged. This is very different in the case of EA hysteresis loops (see figure 3.d)-f)), where the substrate roughness appears to have a dramatic effect on the EA magnetic coercive fields, $\mathrm{H}_{\mathrm{c}}$, as detailed in figure 6 . The average $\mathrm{H}_{\mathrm{c}}$ values increase by $53 \%$ for Kapton and $156 \%$ for PVDF relative to the $\mathrm{H}_{c}$ values of NiFe on Si. Examination of data in figure 6 reveals that roughness in indeed the main contributor to the increase in EA coercive field. However, for all samples the EA coercive fields are also affected by the dc sputtering power as shown in figure 6. The optimal dc sputtering power for our particular deposition system, under the sputtering conditions indicated above, appears to be in the range $50 \mathrm{~W}-75 \mathrm{~W}$, where the largest increases in the $\mathrm{H}_{\mathrm{c}}$ are observed. The effect of deposition power, as well as many other variables involved in sputtering process, is known to greatly influence the final thin film properties. For example, Tang et al. have performed similar experiments in order to study the effects of sputtering process pressure on magnetic properties of NiFe films. They found that coercive fields significantly decrease after lowering the Ar gas pressure and deduced that higher accelerating voltages, which are needed to keep the power values fixed after the drop in the process pressure, was the reason for higher deposition rates and fewer defects [47]. In our experiment these effects are ruled out, as the argon pressure was maintained constant at $3 \times 10^{-3}$ Torr, and the power was also fixed to one of the predetermined values during the coating process. Grain size effects have been shown to 
promote significant changes in the coercive fields of magnetic thin films, with coercive fields increasing proportional to the grain sizes $[25,48]$. In our case, this mechanism is also ruled out as our samples show an increase in the coercive field in thinner films, corresponding to smaller grain sizes. Moreover, a faster growth rate is associated with larger grains and higher coercive fields [25]. In this study, by fabricating samples at variable sputtering power / growth rates (see table 1), we were able to once again rule out the grain size effect as a possible explanation of our results since samples coated at highest sputtering power (100W) and fastest growth rates $(3.8 \AA / \mathrm{s})$ displayed smaller coercive fields than samples coated at lower sputtering powers / growth rates (see figure 6). In the next section we provide theoretical support to our conclusions via micromagnetic modelling of our results.

\section{Theoretical approach}

To analyse the experimental results and the origin of the observed magnetic anisotropy, micromagnetics computations have been used, where surface roughness is incorporated using an effective field model proposed previously [41]. Within this formulation roughness is treated as a perturbation of the magnetostatic energy on a smooth structure, resulting in a configurational anisotropy, which can be extracted as a separate energy density term. Thus if $V$ is the smooth magnetic body without physical roughness, micromagnetics simulations on the body $V$ are performed by including the effective field $\mu_{0} \mathbf{H}=-\partial \varepsilon / \partial \mathbf{M}$, where $\varepsilon$ is the roughness energy density shown in equation 1.

$$
\varepsilon\left(\mathbf{r}_{0}\right)=\varepsilon_{x}\left(\mathbf{r}_{0}\right) m_{x}^{2}+\varepsilon_{y}\left(\mathbf{r}_{0}\right) m_{y}^{2}+\varepsilon_{z}\left(\mathbf{r}_{0}\right) m_{z}^{2} \quad\left(\mathbf{r}_{0} \in V\right)
$$

Here $\boldsymbol{m}=\mathbf{M} /|\mathbf{M}|$ is the magnetisation unit direction vector, and the three orthogonal roughness energy density terms are given in equation 2 , 
$\varepsilon_{i}\left(\mathbf{r}_{0}\right)=\frac{\mu_{0} M_{S}^{2}}{2} \iiint_{\mathbf{r} \in V} N_{i i}\left(\mathbf{r}-\mathbf{r}_{0}\right) G\left(\mathbf{r}, \mathbf{r}_{0}\right) d \mathbf{r} \quad\left(\mathbf{r}_{0} \in V\right), \quad i=x, y, z$

(2)

where

$G\left(\mathbf{r}, \mathbf{r}_{0}\right)=\left\{\begin{array}{cl}\frac{|V|}{\left|V_{R}\right|}-1 & \mathbf{r} \wedge \mathbf{r}_{0} \in V_{R} \\ -1 & \mathbf{r} \vee \mathbf{r}_{0} \in V-V_{R}\end{array}\right.$

In equations 2 and 3, $V_{R} \subset V$ is the magnetic body with physical roughness and volume $\left|V_{R}\right|<$ $|V|, M_{S}$ is the saturation magnetisation, and $N_{i i}(i=x, y, z)$ are the diagonal components of the demagnetizing tensor [49].

For isotropic surface roughness the resulting configurational anisotropy has an easy axis perpendicular to the plane [41]. On the other hand, if the surface roughness profiles are anisotropic, it is expected symmetry axes will be observed in the plane of the sample. This is most readily observed for the NiFe film on the PVDF substrate of figure 2,

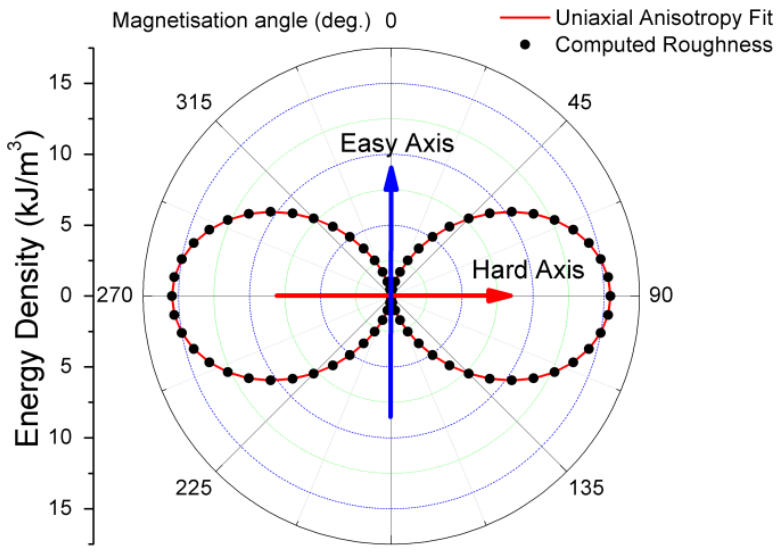

Figure 7. Computed in-plane roughness energy density for the PVDF $\backslash \mathrm{NiFe}$ sample with $6.8 \mathrm{~nm}$ roughness, where the oriented physical surface roughness obtained from AFM scans was imported into the simulations. The results are fitted using the where a strongly anisotropic roughness profile is obtained from AFM scans, uniaxial anisotropy formula with constant $15.5 \mathrm{~kJ} / \mathrm{m}^{3}$. forming an oriented wavy structure in the plane. By incorporating the roughness profile in the effective field model, the in-plane roughness energy density was computed as a function of magnetisation angle $\theta$, shown in figure 7 . This is described very well by the uniaxial anisotropy formula $K \sin ^{2}(\theta)$, where $K \cong 15.5 \mathrm{~kJ} / \mathrm{m}^{3}$, with the easy axis aligned along the wavy surface roughness profile, in agreement with the results shown in figure 3 . The strength 
of this contribution is comparable to that of materials with magneto-crystalline anisotropy, e.g. $6 \mathrm{~kJ} / \mathrm{m}^{3}$ for high quality single-crystal Ni films [50]. Since NiFe has no magnetocrystalline anisotropy, the observed uniaxial anisotropy in figure 3 is attributed to the configurational anisotropy resulting from the anisotropic surface roughness profile. Moreover, the strength of this configurational anisotropy is directly proportional to the roughness level, in agreement with the results shown in figures 3 and 6 , and verified in a previous work as a function of both film thickness and roughness level [40]. The out-of-plane configurational anisotropy persists in the model, however the strength of this is only $2 \%$ of the in-plane anisotropy so it is negligible.

\section{Conclusion}

NiFe thin films on Si, and flexible NiFe thin films on Kapton and PVDF substrates were successfully fabricated by magnetron plasma sputtering technique and their magnetic properties measured experimentally. NiFe films of variable thickness from $15 \mathrm{~nm}$ to $100 \mathrm{~nm}$ showed an emergent effect in which their coercive fields gradually increased in thinner films and remained broadly unchanged in $100 \mathrm{~nm}$ thin films. The effect was more pronounced for flexible, rougher substrates, indicating that roughness of a substrate influences magnetic coercivity and the anisotropy of the film. We hypothesized that the observed effect was due to a surface induced magnetic anisotropy. This hypothesis was then experimentally confirmed by fabricating $15 \mathrm{~nm} \mathrm{NiFe}$ thin films deposited on Silicon, Kapton and PVDF. We found that the coercive fields increase in line with the roughness of substrates. In addition, a hard axis and easy axis emerged only in $15 \mathrm{~nm}$ thin films deposited onto flexible rough substrates. Identical $15 \mathrm{~nm} \mathrm{NiFe}$ films on Si substrates showed no magnetic anisotropy and no variation of the coercive fields. It is important to state that our samples were grown under no external magnetic field, they were not annealed or otherwise treated in any way that could explain the 
emergence of the magnetic anisotropy. Theoretical simulations using Lepadatu's model of the surface roughness effect also supported our conclusions. The ability to use surface roughness to tune the properties of magnetic thin films is of great importance as it offers more versatility in the fabrication of complex nano-structured sensors and devices based on magnetic thin films, and we hope that this work will stimulate future studies in this area.

\section{Acknowledgments}

The authors would like to acknowledge the financial support to this work received from Kurt J. Lesker Ltd and the University of Portsmouth via a PhD studentship funding.

\section{References}

[1] M. Ohring, Materials Science of Thin Films, 2nd ed. edition, Academic Press, 2014.

[2] S. Masudy-Panah, S. Zhuk, H.R. Tan, X. Gong, G.K. Dalapati, Palladium nanostructure incorporated cupric oxide thin film with strong optical absorption, compatible charge collection and low recombination loss for low cost solar cell applications, Nano Energy. 46 (2018) 158-167. doi:10.1016/j.nanoen.2018.01.050.

[3] H. Song, X. Zhan, D. Li, Y. Zhou, B. Yang, K. Zeng, J. Zhong, X. Miao, J. Tang, Rapid thermal evaporation of Bi2S3 layer for thin film photovoltaics, Sol. Energy Mater. Sol. Cells. 146 (2016) 1-7. doi:10.1016/j.solmat.2015.11.019.

[4] J. Lindahl, J. Keller, O. Donzel-Gargand, P. Szaniawski, M. Edoff, T. Törndahl, Deposition temperature induced conduction band changes in zinc tin oxide buffer layers for $\mathrm{Cu}$ (In,Ga)Se2 solar cells, Sol. Energy Mater. Sol. Cells. 144 (2016) 684-690. doi:10.1016/j.solmat.2015.09.048.

[5] F.J. Willars-Rodríguez, I.R. Chávez-Urbiola, M.A. Hernández-Landaverde, P. Vorobiev, R. RamírezBon, Y.V. Vorobiev, Effects of tin-doping on cadmium sulfide (CdS:Sn) thin-films grown by light-assisted chemical bath deposition process for solar photovoltaic cell, Thin Solid Films. 653 (2018) 341-349. doi:10.1016/j.tsf.2018.03.046.

[6] M. Smeets, K. Wilken, K. Bittkau, H. Aguas, L. Pereira, E. Fortunato, R. Martins, V. Smirnov, Flexible thin film solar cells on cellulose substrates with improved light management, Phys. Status Solidi A. 214 (n.d.) 1700070. doi:10.1002/pssa.201700070.

[7] P.K. Mohseni, G. Lawson, A. Adronov, R.R. LaPierre, Hybrid GaAs-Nanowire \#x2013;CarbonNanotube Flexible Photovoltaics, IEEE J. Sel. Top. Quantum Electron. 17 (2011) 1070-1077. doi:10.1109/JSTQE.2010.2048097.

[8] L. Li, S. Liu, H. Zhou, Q. Lei, K. Qian, All solid-state thin-film lithium-ion battery with $\mathrm{Ti} / \mathrm{ZnO} / \mathrm{LiPON} / \mathrm{LiMn} 2 \mathrm{O} 4 / \mathrm{Ti}$ structure fabricated by magnetron sputtering, Mater. Lett. 216 (2018) 135-138. doi:10.1016/j.matlet.2017.12.131. 
[9] Y. Matsuda, N. Kuwata, J. Kawamura, Thin-film lithium batteries with $0.3-30 \mu \mathrm{m}$ thick LiCoO2 films fabricated by high-rate pulsed laser deposition, Solid State Ion. 320 (2018) 38-44.

doi:10.1016/j.ssi.2018.02.024.

[10] Y. Shacham-Diamand, T. Osaka, Y. Okinaka, A. Sugiyama, V. Dubin, 30years of electroless plating for semiconductor and polymer micro-systems, Microelectron. Eng. 132 (2015) 35-45. doi:10.1016/j.mee.2014.09.003.

[11] A. Piegari, F. Flory, eds., Optical Thin Films and Coatings: From Materials to Applications, Woodhead Publishing, Cambridge, UK, 2013.

[12] M. Nakata, Y. Nakajima, H. Tsuji, T. Takei, Y. Fujisaki, T. Yamamoto, High Performance oxide thinfilm transistor for large-screen, high-resolution organic light-emitting diode display, in: 2016 IEEE Ind. Appl. Soc. Annu. Meet., 2016: pp. 1-5. doi:10.1109/IAS.2016.7731901.

[13] D.-S. Oh, K.-H. Kang, H.-J. Kim, J.-K. Kim, M.-S. Won, D.-E. Kim, Tribological characteristics of micro-ball bearing with V-shaped grooves coated with ultra-thin protective layers, Tribol. Int. 119 (2018) 481490. doi:10.1016/j.triboint.2017.11.014.

[14] Y. Jing, H. Luo, P. Huang, L. Qin, U-type piezoelectric thin-film microactuator for hard disk drives, IEEE Trans. Magn. 41 (2005) 4309-4314. doi:10.1109/TMAG.2005.854235.

[15] S.-W. Jung, B.S. Na, I.-K. You, J.B. Koo, B.-D. Yang, J.-M. Oh, Inkjet-printed organic thin-film transistor and antifuse capacitor for flexible one-time programmable memory applications, J. Korean Phys. Soc. 64 (2014) 74-78. doi:10.3938/jkps.64.74.

[16] J. Shi, J. Zhu, L. Yin, H. Jiang, C. Lu, X. Gao, X. Bao, J. Li, The Study of Fe83Ga17 Films act as Magnetostrictive Actuator on PZT Substrate, IEEE Trans. Magn. 53 (2017) 1-4. doi:10.1109/TMAG.2017.2716405.

[17] H. Wu, H. Yu, High frequency magnetic thin film inductor integrated on flexible organic substrates, in: 2017 IEEE Int. Magn. Conf. INTERMAG, 2017: pp. 1-1. doi:10.1109/INTMAG.2017.8007781.

[18] D.N. Kossyvakis, S.G. Vassiliadis, C.G. Vossou, E.E. Mangiorou, K.I. Prekas, S.M. Potirakis, A wearable magnetic sensing device for identifying the presence of static magnetic fields, Measurement. 109 (2017) 44-50. doi:10.1016/j.measurement.2017.05.044.

[19] N.N. Mai-Khanh, T. Iizuka, S. Nakajima, K. Asada, High-sensitivity micro-magnetic probe for the applications of safety and security, in: 2017 7th Int. Conf. Integr. Circuits Des. Verification ICDV, 2017: pp. 10-15. doi:10.1109/ICDV.2017.8188628.

[20] N.H. Touidjen, B. Bendahmane, M.L. Zeggar, F. Mansour, M.S. Aida, SnO2 thin film synthesis for organic vapors sensing at ambient temperature, Sens. Bio-Sens. Res. 11 (2016) 52-57.

doi:10.1016/j.sbsr.2016.11.001.

[21] Y. Zhang, J. Qi, Y. Wang, Y. Tian, J. Zhang, T. Hu, M. Wei, Y. Liu, J. Yang, Tuning magnetic properties of BiFeO3 thin films by controlling Mn doping concentration, Ceram. Int. 44 (2018) 6054-6061. doi:10.1016/j.ceramint.2017.12.230.

[22] K. Sun, Y. Dai, Y. Yang, Z. Yu, H. Liu, X. Jiang, Z. Lan, Influence of substrate type on the property of nickle-zinc ferrite thin films, Ceram. Int. 42 (2016) 3028-3032. doi:10.1016/j.ceramint.2015.10.089.

[23] J. Sagar, C. Yu, C. Pelter, J. Wood, L. Lari, A. Hirohata, K. O’Grady, Effect of Seed Layers on Polycrystalline Co2FeSi Thin Films, IEEE Trans. Magn. 48 (2012) 4006-4009.

doi:10.1109/TMAG.2012.2202890.

[24] Y. Kumar, J. Tripathi, S. Tripathi, D. Kumar, R. Bisen, K.C. Ugochukwu, A. Sharma, Influence of annealing on the structural and magnetic properties of Fe thin film Sandwiched between $\mathrm{Au}$ and $\mathrm{Si}$, Vacuum. 153 (2018) 221-224. doi:10.1016/j.vacuum.2018.04.018.

[25] M. Vopsaroiu, G.V. Fernandez, M.J. Thwaites, J. Anguita, P.J. Grundy, K. O’Grady, Deposition of polycrystalline thin films with controlled grain size, J. Phys. Appl. Phys. 38 (2005) 490. doi:10.1088/0022$3727 / 38 / 3 / 022$.

[26] M. Vopsaroiu, M. Georgieva, P.J. Grundy, M.J. Thwaites, K. O’Grady, Growth rate effects in soft CoFe films, in: INTERMAG Asia 2005 Dig. IEEE Int. Magn. Conf. 2005, 2005: pp. 45-46. doi:10.1109/INTMAG.2005.1463451.

[27] L. Li, S. Zhang, Z. Yang, E.E.S. Berthold, W. Chen, Recent advances of flexible perovskite solar cells, J. Energy Chem. 27 (2018) 673-689. doi:10.1016/j.jechem.2018.01.003.

[28] M. Nakata, G. Motomura, Y. Nakajima, T. Takei, H. Tsuji, H. Fukagawa, T. Shimizu, T. Tsuzuki, Y. Fujisaki, T. Yamamoto, Development of flexible displays using back-channel-etched In-Sn-Zn-O thin-film 
transistors and air-stable inverted organic light-emitting diodes, J. Soc. Inf. Disp. 24 (n.d.) 3-11. doi:10.1002/jsid.408.

[29] S. Saritas, M. Kundakci, O. Coban, S. Tuzemen, M. Yildirim, Ni: Fe2O3, Mg: Fe2O3 and Fe2O3 thin films gas sensor application, Phys. B Condens. Matter. 541 (2018) 14-18. doi:10.1016/j.physb.2018.04.028.

[30] D. Maji, S. Das, Integrated Flexible Thin Film Sensor Around Angiographic Catheter for Flow Detection, Procedia Technol. 27 (2017) 221-223. doi:10.1016/j.protcy.2017.04.093.

[31] A. Paliwal, A. Sharma, M. Tomar, V. Gupta, Magneto-optical properties of BiFeO3 thin films using surface plasmon resonance technique, Phys. B Condens. Matter. 448 (2014) 120-124.

doi:10.1016/j.physb.2014.02.031.

[32] P. Taptimthong, J. Rittinger, M.C. Wurz, L. Rissing, Flexible Magnetic Writing / Reading System: Polyimide Film as Flexible Substrate, Procedia Technol. 15 (2014) 230-237. doi:10.1016/j.protcy.2014.09.076. [33] L.Y. Fetisov, I.A. Baraban, Y.K. Fetisov, D.A. Burdin, M.M. Vopson, Nonlinear magnetoelectric effects in flexible composite ferromagnetic - Piezopolymer structures, J. Magn. Magn. Mater. 441 (2017) 628634. doi:10.1016/j.jmmm.2017.06.013.

[34] J.M.D. Coey, Magnetism and Magnetic Materials, Cambridge University Press, Cambridge, 2010. [35] S.K. Chen, F.T. Yuan, S.N. Hsiao, H.C. Chang, C.Y. Liou, W.C. Chang, Thickness dependence of longitudinal coercivity in Fe-Pt-Al thin films, J. Magn. Magn. Mater. 282 (2004) 198-201. doi:10.1016/j.jmmm.2004.04.045.

[36] T. Shima, K. Takanashi, Y.K. Takahashi, K. Hono, G.Q. Li, S. Ishio, High coercivity and magnetic domain observation in epitaxially grown particulate FePt thin films, J. Magn. Magn. Mater. 266 (2003) 171177. doi:10.1016/S0304-8853(03)00468-2.

[37] Y. Cao, C. Zhou, Dependence of coercivity on ferromagnetic layer thickness in FeNiCr/Cr bilayers, J. Magn. Magn. Mater. 369 (2014) 5-8. doi:10.1016/j.jmmm.2014.06.012.

[38] S. Iwatsubo, T. Takahashi, M. Nao, Effect of surface roughness on magnetic properties of Fe films deposited by dual ion beam sputtering, Thin Solid Films. 343-344 (1999) 67-70. doi:10.1016/S00406090(98)01705-2.

[39] H. Xie, L. Pan, X. Cheng, Z. Zhu, H. Feng, J. Wang, Q. Liu, Effect of substrate roughness on the magnetic properties of CoFeB films, J. Magn. Magn. Mater. 461 (2018) 19-22.

doi:10.1016/j.jmmm.2018.04.046.

[40] M.M. Vopson, J. Naylor, T. Saengow, E.G. Rogers, S. Lepadatu, Y.K. Fetisov, Development of flexible Ni80Fe20 magnetic nano-thin films, Phys. B Condens. Matter. 525 (2017) 12-15. doi:10.1016/j.physb.2017.09.005.

[41] S. Lepadatu, Effective field model of roughness in magnetic nano-structures, J. Appl. Phys. 118 (2015) 243908. doi:10.1063/1.4939093.

[42] Kurt J. Lesker Company | Physical Vapor Deposition Systems | Vacuum Science Is Our Business, (n.d.). https://www.lesker.com/newweb/ped/physical-vapor-deposition-systems.cfm (accessed June 25, 2018).

[43] T.Y. Hin, C. Liu, P.P. Conway, Surface characterisation of plasma treated flexible substrates for waveguide-on-flex application, Surf. Coat. Technol. 203 (2009) 3741-3749.

doi:10.1016/j.surfcoat.2009.06.015.

[44] A. Bouhamed, A.M. Kia, S. Naifar, V. Dzhagan, C. Müller, D.R.T. Zahn, S. Choura, O. Kanoun, Tuning the adhesion between polyimide substrate and MWCNTs/epoxy nanocomposite by surface treatment, Appl. Surf. Sci. 422 (2017) 420-429. doi:10.1016/j.apsusc.2017.05.177.

[45] D.C.M. Rodrigues, A.B. Klautau, A. Edström, J. Rusz, L. Nordström, M. Pereiro, B. Hjörvarsson, O. Eriksson, Magnetic anisotropy in Permalloy: hidden quantum mechanical features, ArXiv170205414 Cond-Mat. (2017). http://arxiv.org/abs/1702.05414 (accessed June 13, 2018).

[46] L.F. Yin, D.H. Wei, N. Lei, L.H. Zhou, C.S. Tian, G.S. Dong, X.F. Jin, L.P. Guo, Q.J. Jia, R.Q. Wu, Magnetocrystalline anisotropy in permalloy revisited, Phys. Rev. Lett. 97 (2006) 067203. doi:10.1103/PhysRevLett.97.067203.

[47] X.-L. Tang, H. Su, H.-W. Zhang, Z.-Y. Zhong, Y.-L. Jing, Improving the morphological and magnetic properties of permalloy films by adopting ultra-low-pressure sputtering, Thin Solid Films. 550 (2014) 616-620. doi:10.1016/j.tsf.2013.11.005.

[48] M. Vopsaroiu, M. Georgieva, P.J. Grundy, G. Vallejo Fernandez, S. Manzoor, M.J. Thwaites, K. O’Grady, Preparation of high moment CoFe films with controlled grain size and coercivity, J. Appl. Phys. 97 (2005) 10N303. doi:10.1063/1.1855276. 
[49] A. Newell, W. Williams, D. Dunlop, A generalization of the demagnetizing tensor for nonuniform magnetization, J. Geophys. Res. 98 (1993) 9551-9555. doi:10.1029/93JB00694.

[50] E. Secemski, J.C. Anderson, Magnetic anisotropy in single-crystal nickel films, J. Phys. Appl. Phys. 4 (1971) 574. doi:10.1088/0022-3727/4/4/316. 


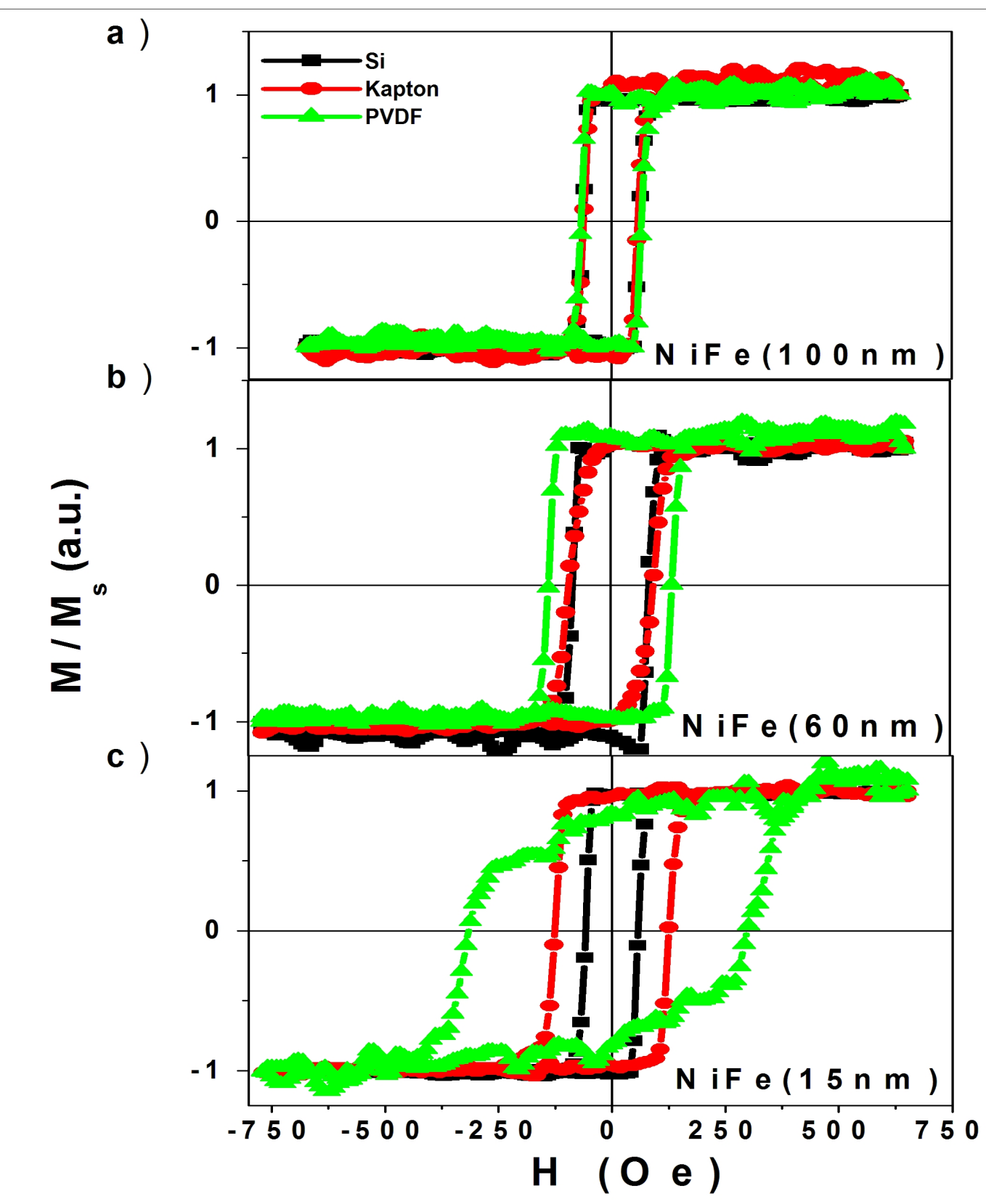


a)

\section{Silicon substrate}

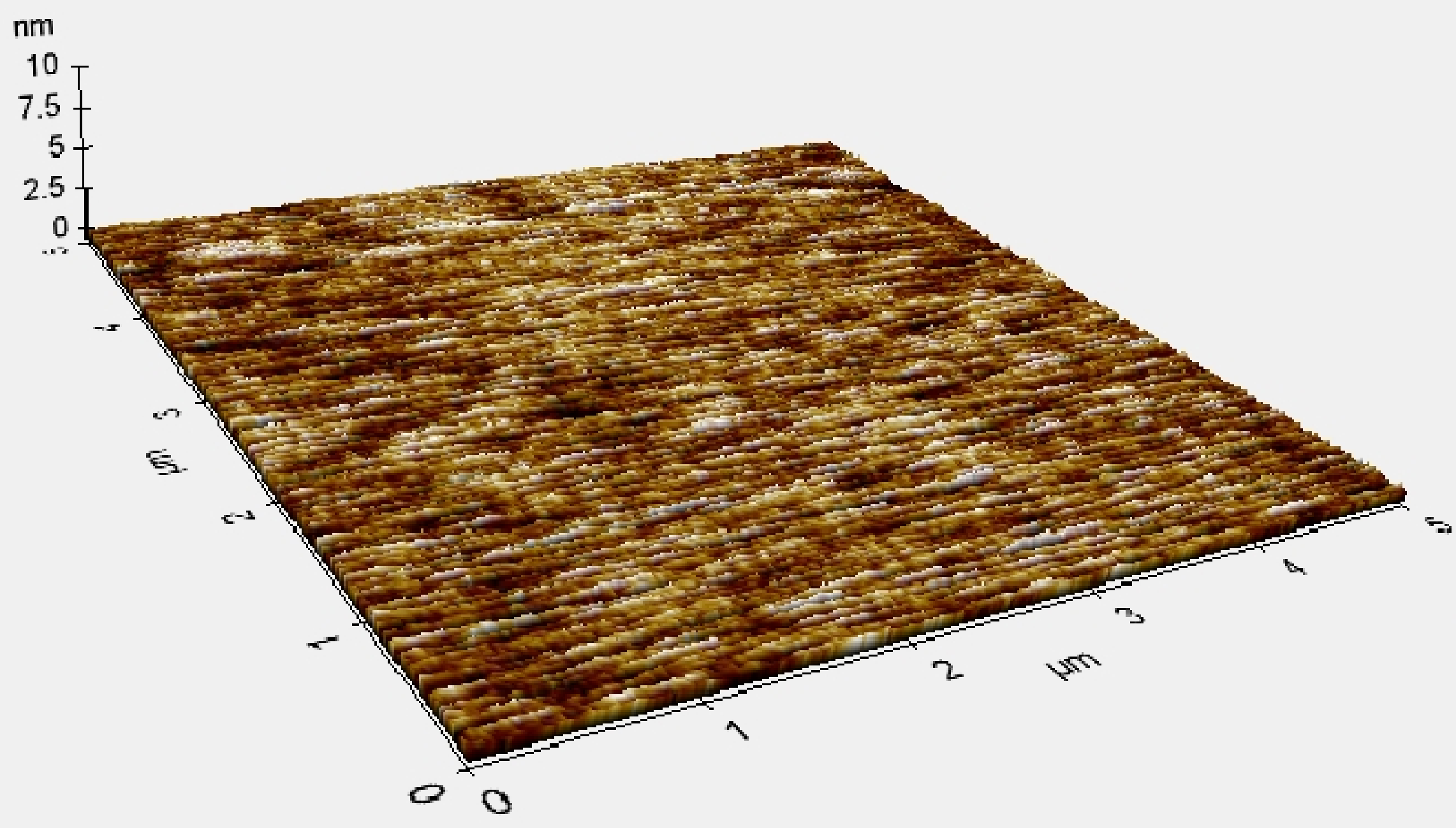




\section{b) Kapton substrate}

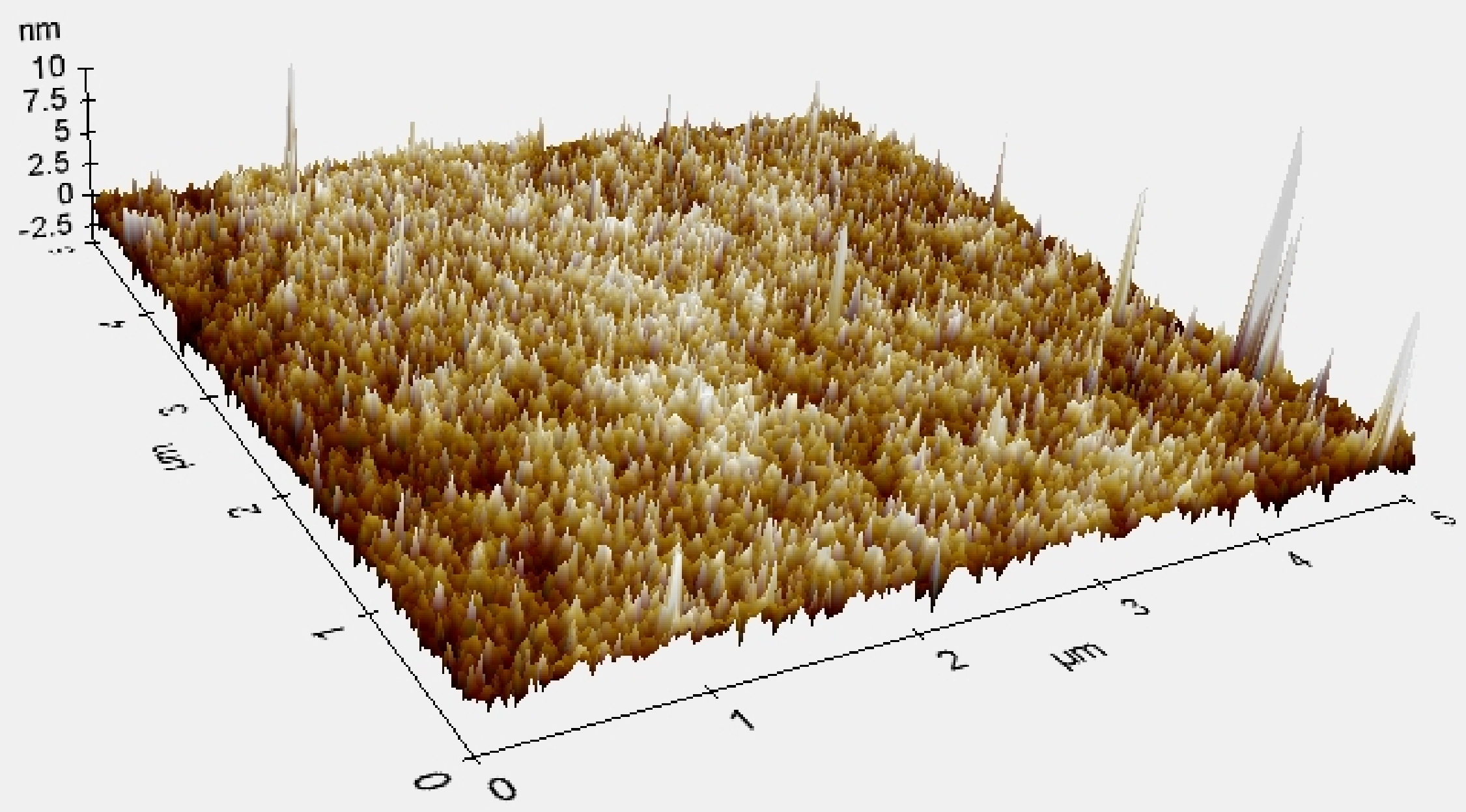


c) PVDF substrate

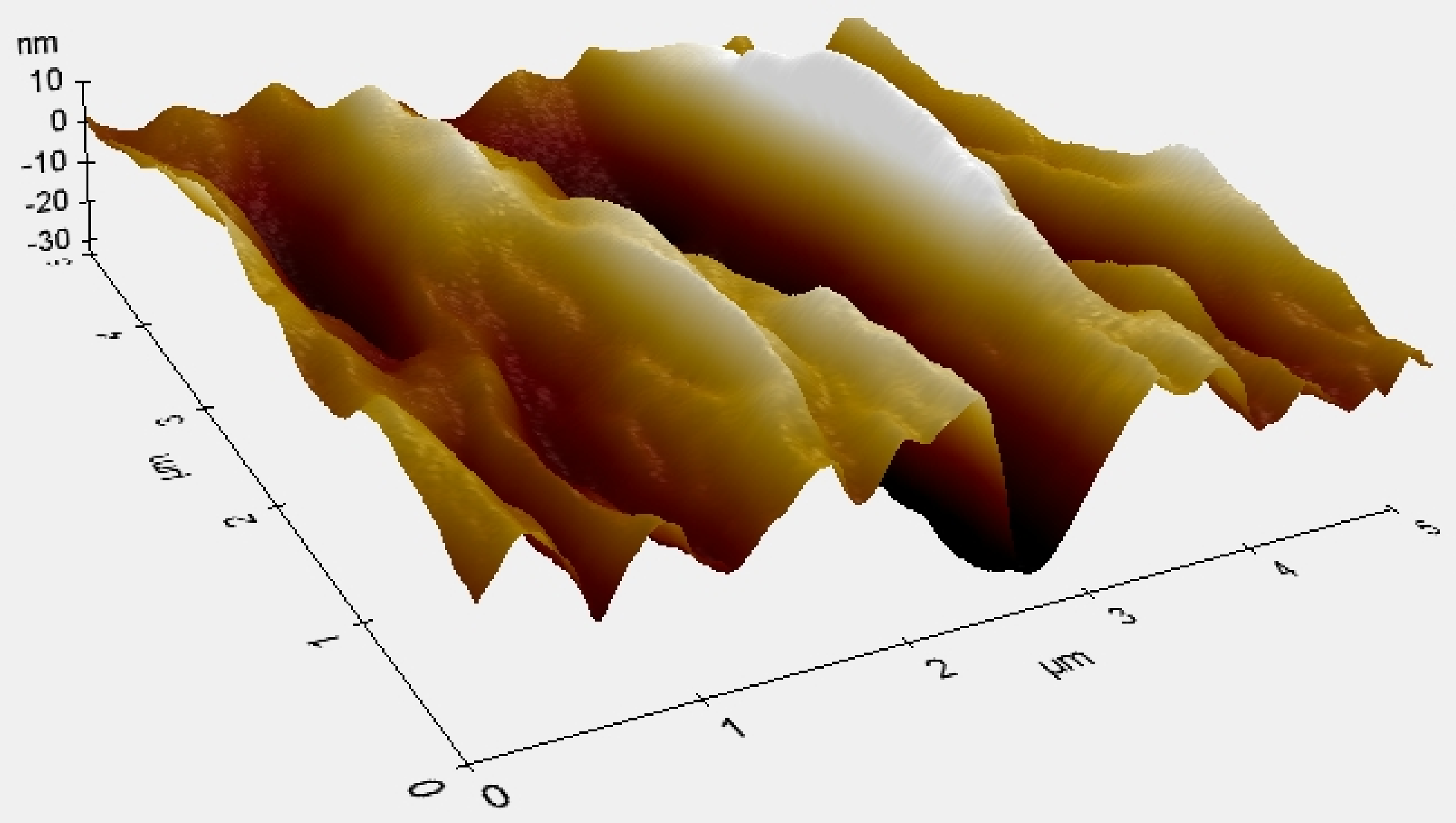


$\underline{H}$ ard axis

a)
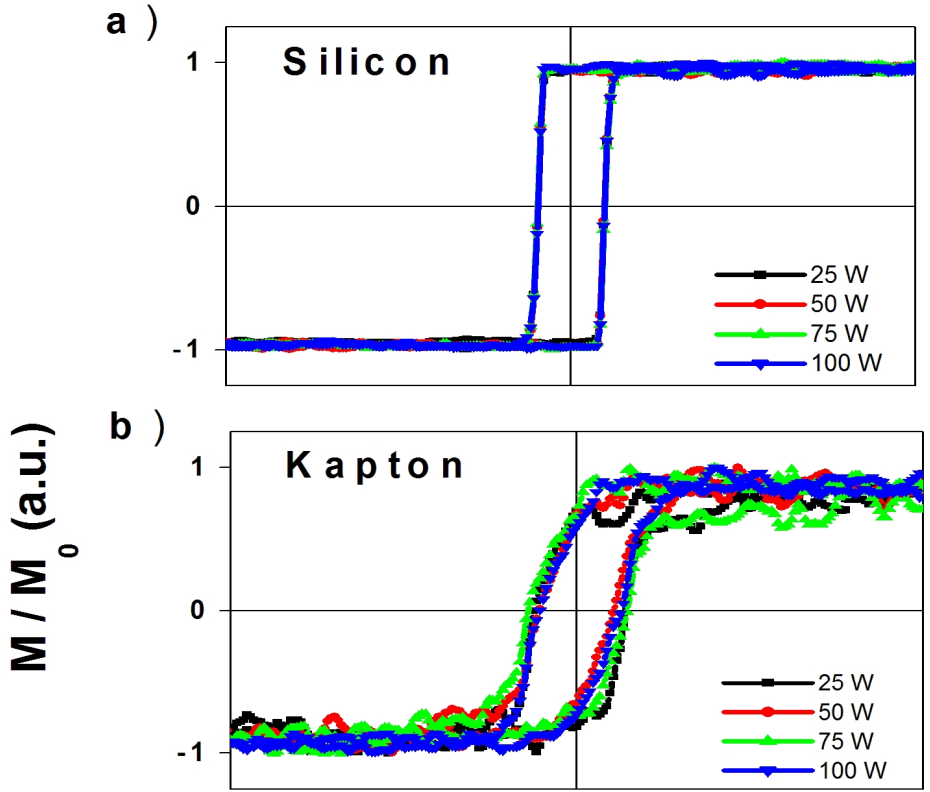

c )

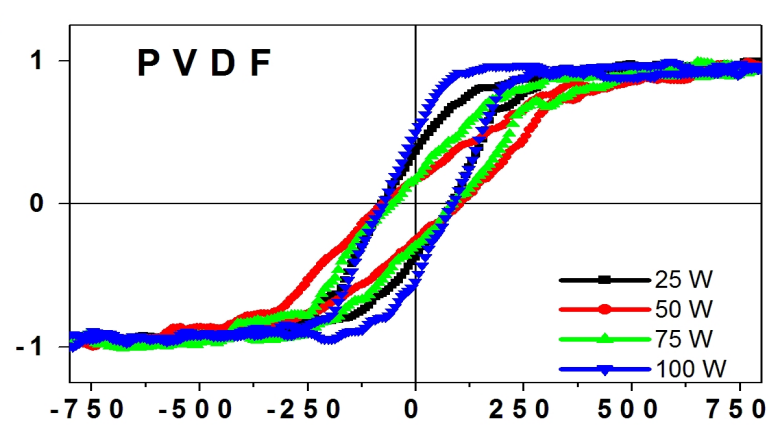

Easy a $x$ is

d )

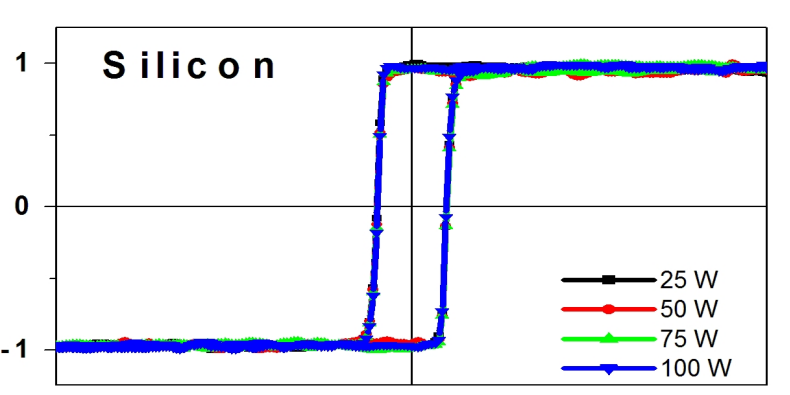

e)

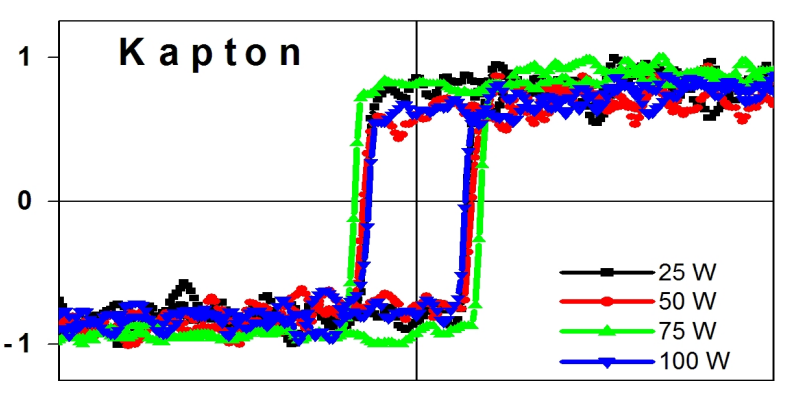

f)

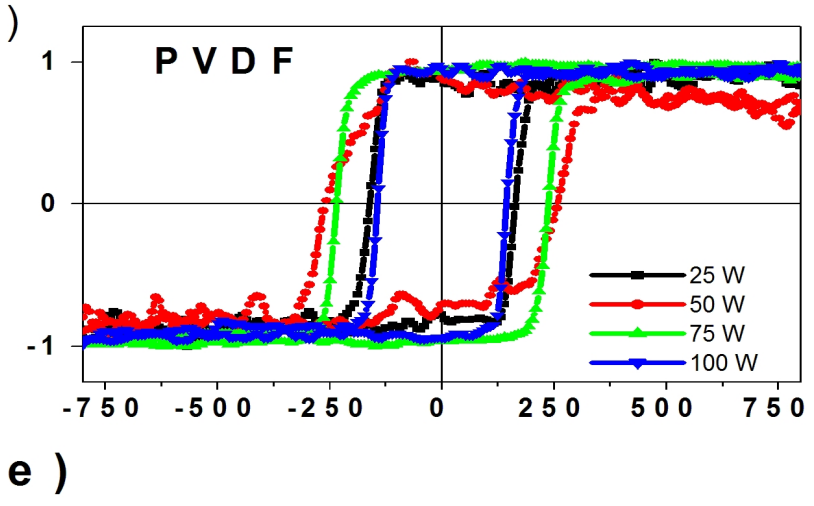




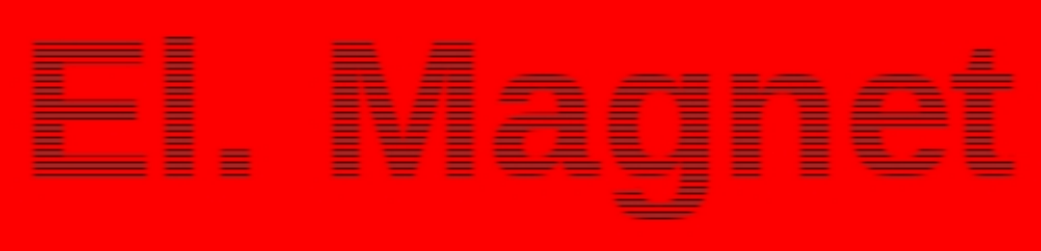




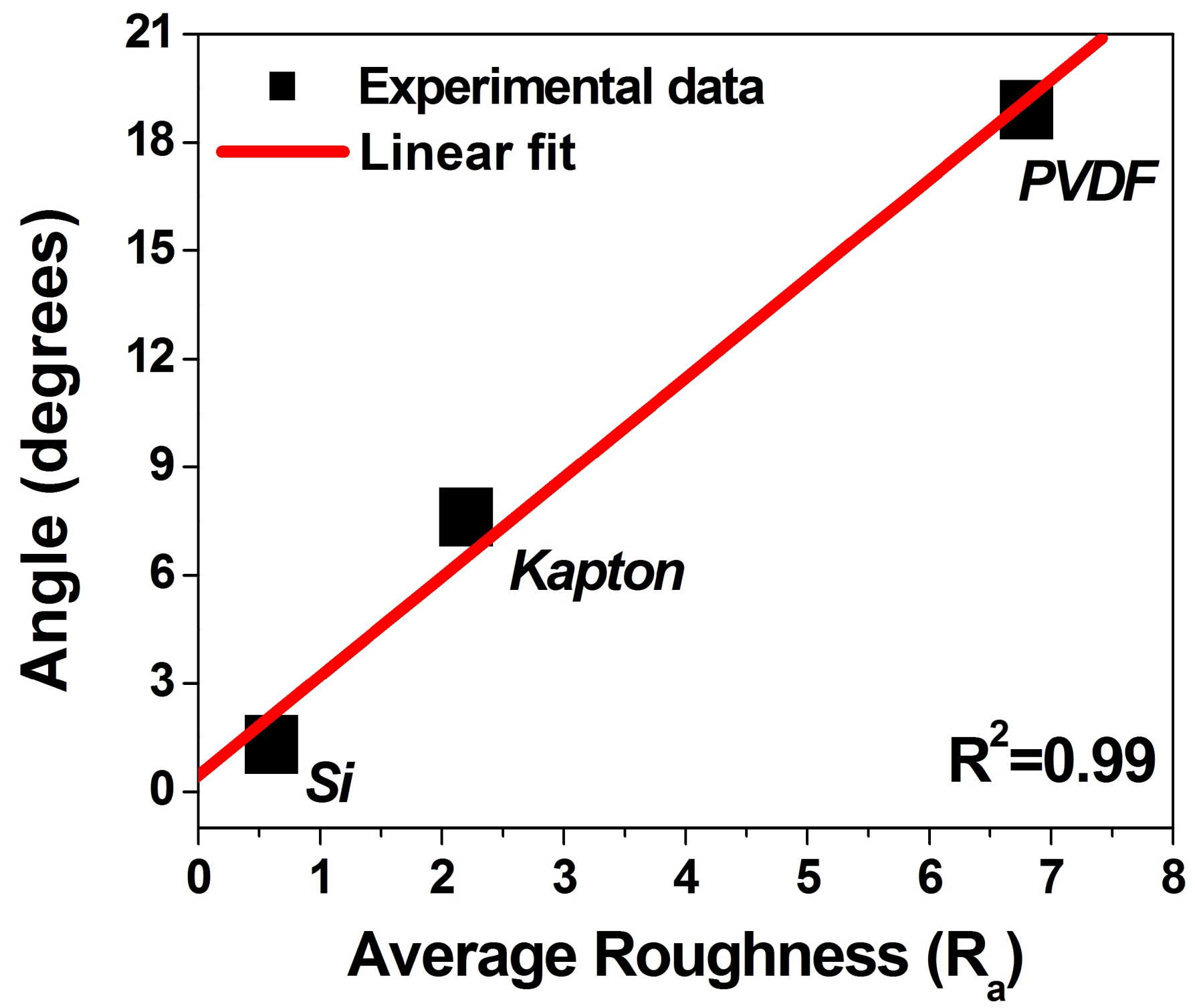


Coercivity values for $15 \mathrm{~nm}$ NiFe - Easy axis

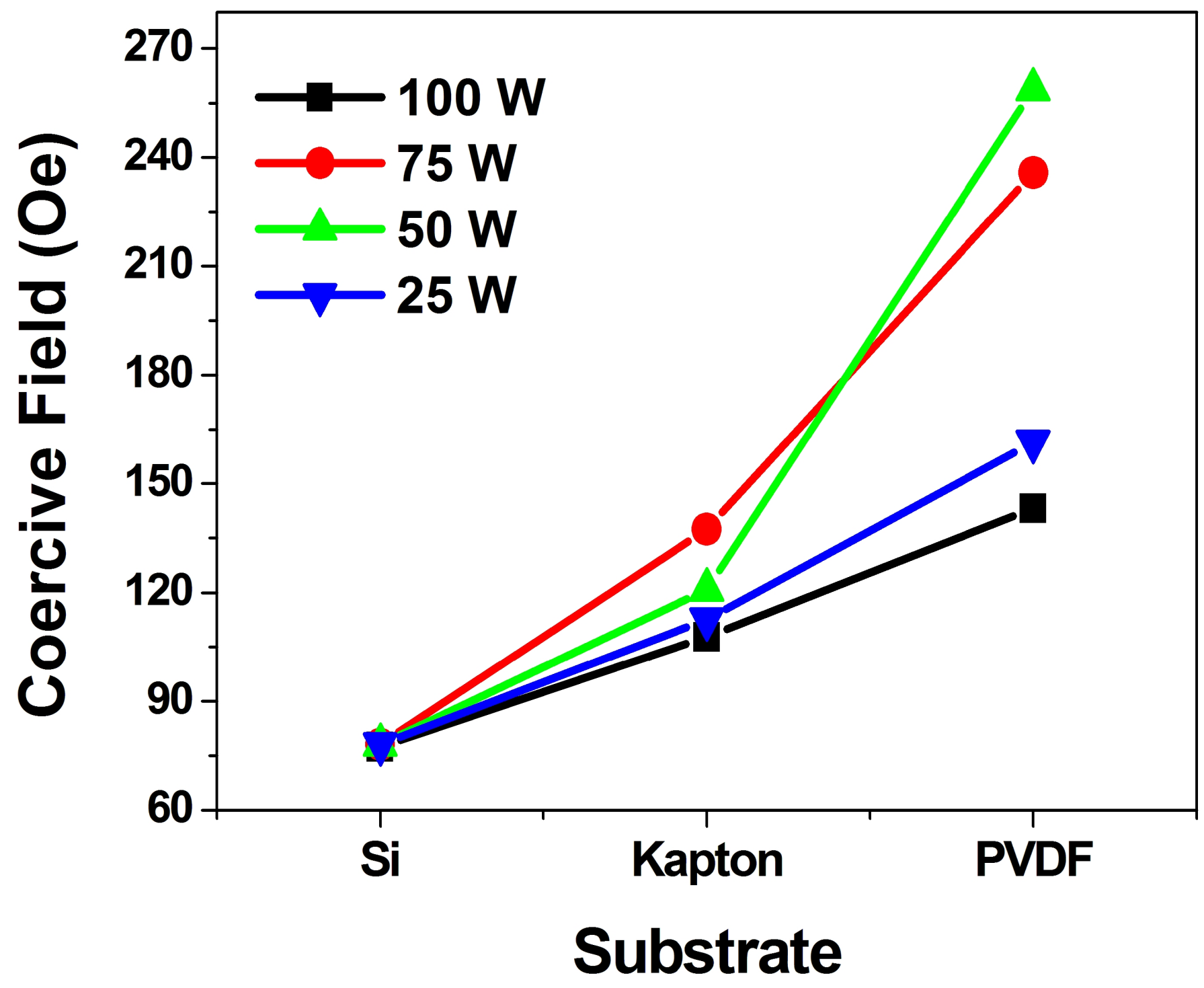




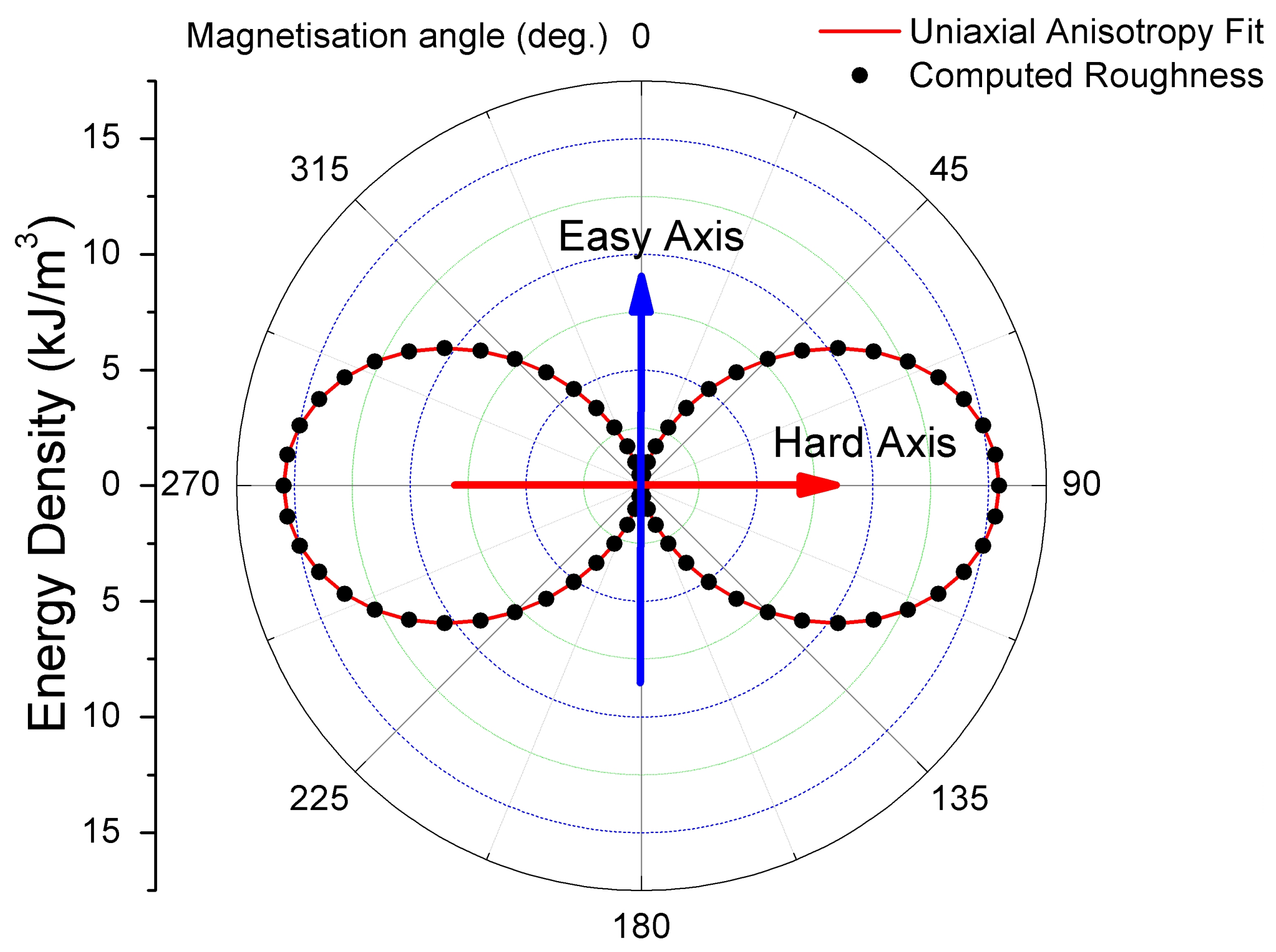

